\title{
Evidence of species-specific habitat selectivity of Acropora corals based on identification of new recruits by two molecular markers
}

\author{
Go Suzuki $^{1, *}$, Takeshi Hayashibara ${ }^{2}$, Yoshihisa Shirayama ${ }^{3}$, Hironobu Fukami ${ }^{3}$ \\ ${ }^{1}$ Division of Applied Biosciences, Graduate School of Agriculture, Kyoto University, Kyoto 606-8502, Japan \\ ${ }^{2}$ Ishigaki Tropical Station, Seikai National Fisheries Research Institute, Fisheries Research Agency, Okinawa 907-0451, Japan \\ ${ }^{3}$ Seto Marine Biological Laboratory, Field Science Education and Research Center, Kyoto University, Wakayama 649-2211, Japan
}

\begin{abstract}
One of the most abundant genera of scleractinian corals, Acropora, shows considerable zonation along reef slopes. The zones are thought to be established by both selective larval settlement and post-settlement selection. The latter has been credited as more important, possibly due to the obvious relationship between colony shapes and habitat-specific environmental stress. However, there is no evidence that the former has less influence on the creation of the zones. To test the hypothesis that larvae settle selectively on species-specific suitable habitat, we identified recruits using mitochondrial and nuclear molecular markers. A 2-step molecular sorting process successfully identified the 7 most dominant species in the area. Comparing the species composition of 3 different depths, the distribution of the settlement of the 3 dominant species A. digitifera, A. hyacinthus and A. tenuis was significantly related to adult zonation, suggesting that Acropora larvae selectively settle on the suitable habitat. This is the first in situ evidence showing selective settlement of coral larvae, and from it we can conclude that the initial stage of the life cycle plays an important role in establishing habitat segregation at the species level in Acropora.
\end{abstract}

KEY WORDS: Reef coral · Acropora $\cdot$ Settlement $\cdot$ Zonation · Molecular marker $\cdot$ Habitat selection Resale or republication not permitted without written consent of the publisher

\section{INTRODUCTION}

Tropical and subtropical shallow reef corals grow in specific areas causing the appearance of patterns or zones. This zonation occurs along the various coastal gradients: land-ocean slopes (Done 1982), from the head to entrances of a bay (Adjeroud 1997), or depth (Sheppard 1980, Dollar 1982, Graus \& Macintyre 1989, Adjeroud 1997). Depth gradient zonation can be distinguished at different taxonomic levels: within a single species (Carlon 2002), among species (Wallace \& Dale 1979) or among higher taxa. Various environmental factors such as wave stress (Dollar 1982, Graus \& Macintyre 1989), light regime (Graus \& Macintyre 1989, Titlyanov \& Latypov 1991) and sedimentation (Rogers 1990) are suggested to determine the pattern of coastal zonation. The role of larval settlement has long been ignored for corals, although it has been observed for other marine invertebrates. For barnacles, variations in settlement were more important in regulating communities in regions where settlement was light than in regions where settlement was heavy (Underwood \& Denley 1984). More recently, as the habitat selection process influenced by various factors such as the presence of conspecific (Jeffery 2002) and microbial community (Thiyagarajan et al. 2006) has been revealed, the importance of pre-settlement events in determining zonation is highlighted in intertidal barnacles.

In the last decade, it has been suggested that larval settlement may be equivalent to or even more important than post-settlement selection on depth gradient zonation at the higher taxonomic level. For example, a series of studies in the Great Barrier Reef indicated 
that larval settlement success is more important to species-specific distribution than differences in postsettlement mortality among species (Babcock \& Mundy 1996, Mundy \& Babcock 1998, 2000, Baird et al. 2003). They found that larvae settled in conditions that matched the adult habitat in laboratory experiments that compared shallow-water species (Goniastrea aspera, G. favulus and Acropora tenuis; Mundy \& Babcock 1998, G. aspera and G. retiformis; Baird et al. 2003) and shade-preferred or deep-water species (Oxypora lacera and Montipora peltiformis, Mundy \& Babcock 1998; Fungia horrida and F. repanda, Baird et al. 2003). The significance of selectivity during the initial life stage has also been suggested at the intraspecies level. Carlon (2002) concluded that larval supply may establish the vertical distribution of the brooding coral Favia fragum, examining colony fecundity according to depth and larval choice of habitat. Raimondi \& Morse (2000) attained a similar result in a pre- and post-settlement experiment using the Caribbean brooding coral Agaricia humilis. Despite these suggestions of the importance of selective settlement, there is no direct evidence based on field research, nor is there evidence of the zonation among species within a genus.

The genus Acropora, one of the most dominant groups on the Indo-Pacific reefs, includes $>100$ species and represents clear species-specific zonation. So far, no reports have recognized larval settlement as a significant factor in establishing patterns of zonation in this genus, probably because it is generally thought that post-settlement survival is more important due to the remarkable differences in colony morphology. For example, encrusting or digitate species dominate exposed habitats, while branching species are more noticeable in calmer water. The primary barrier to investigating pre-settlement choice is the difficulty of species identification of new coral recruits especially within the first year of settlement. Few morphological studies on juveniles have been performed; there are only 3 families (Acroporidae, Pocilloporidae and Poritidae) that are distinguishable, and genus-level identification is limited within these families (Baird \& Babcock 2000, Babcock et al. 2003). To overcome these issues, we used molecular-based species identification techniques to recognize Acropora recruits.

Molecular techniques have been used to identify larvae of numerous marine organisms (e.g. asteroids, Evans et al. 1998; bivalves, Andre et al. 1999; fishes, Lindstrom 1999). In the scleractinian corals, Shearer \& Coffroth (2006) analyzed recruits on the Caribbean reefs using a PCR-restriction fragment length polymorphism (RFLP) method for species identification. Species composition was not acquired in their study as the marker used highlighted species complexes rather than single species. The molecular identification of Acropora species was expected to be more difficult than that of the Caribbean corals due to the large number of species and the species-level polyphyly (van Oppen et al. 2001) found within the genus. To identify Acropora species, we adopted a 2-phased approach using both mitochondrial and nuclear DNA sequences as molecular markers, because the former is unsuitable for differentiation between closely related species and the latter has variations too large to compare all species in the genus. The aims of our study were to identify new recruits of Acropora at the species level, compare species composition among different depths, and verify the hypothesis that the larvae settle selectively with species-specific preference for their lifetime habitat.

\section{MATERIALS AND METHODS}

Study area and Acropora coverage. Ishigaki Island $\left(24^{\circ} 27^{\prime} \mathrm{N}, 124^{\circ} 12^{\prime} \mathrm{E}\right)$ is located in the southwest of the Ryukyu Archipelago. The Tomino and Urasoko Reefs, where the recruitment research was conducted, lie in the middle of the northern shoreline approximately $2 \mathrm{~km}$ apart (Fig. 1a). In this area, 16 families, 59 genera, and 234 hermatypic coral species are reported, and with 40 species, Acropora is the most abundant genus (Fujioka 1998). Coral zonation is observed on Tomino Reef but not on Urasoko Reef, where there is a shallow inner reef (up to $2 \mathrm{~m}$ depth). To estimate Acropora distribution quantitatively, 3 replicate $5 \mathrm{~m}$ line transects were set at 4 depths on Tomino Reef: the reef crest $(1.5 \mathrm{~m})$, shallow $(2.5 \mathrm{~m})$, middle $(5.5 \mathrm{~m})$ and deep $(11 \mathrm{~m})$ (Fig. 1b), and 1 depth on Urasoko Reef: shallow $(1.5 \mathrm{~m})$. To maintain the homogeneity of ecological conditions along the survey, transects were run parallel to the shoreline. Each $50 \mathrm{~cm}$ quadrat was photographed along the transect and Acropora were identified to species level, and all others to genus. Coral coverage of each Acropora species was evaluated by the software program Coral Point Count with Excel extension (CPCe; Kohler \& Gill 2006). The stratified random method ( 2 rows and 5 columns with 5 random points in each cell: total 50 points on each image) was used for determining the distribution of random points. Corals (or no coral area including other sessile organisms) at the points were identified and the ratio of the number of occupied points was calculated as the coverage.

Collection of adult colonies and recruits. Between 5 and 20 adult colonies of each dominant Acropora species were collected from Tomino Reef. Each colony was tied with a numbered tag and photographed. A small piece (roughly $0.1 \mathrm{~cm}^{3}$ ) was broken 


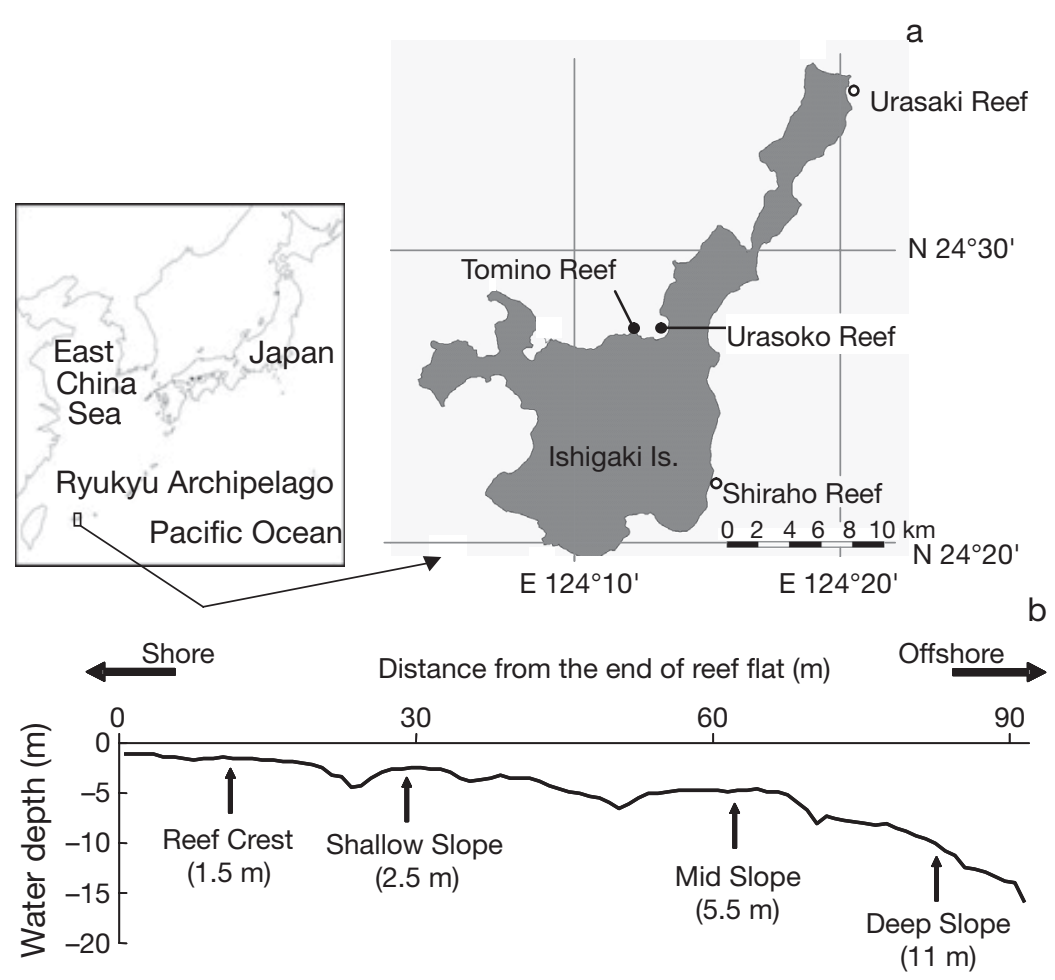

Fig. 1. Study area. (a) Ishigaki Island, (b) cross-section drawing of Tomino Reef. The reef crest was surveyed only during the assessment of coral coverage

were counted and their position on the plate mapped. Recruits of Acropora were distinguished from those of other corals by morphological traits. Only plates retrieved in 2006 were used for DNA analysis. Five recruits on each plate were randomly removed with a cutter knife and preserved in $30 \mu \mathrm{l}$ guanidine solution. If a plate had $<5$ recruits, all living specimens were sampled. Further, as some plates disappeared due to wave action, the number of analyzed specimens is different among depths.

Genetic identification. Each piece of adult coral tissue (collected from 104 colonies in total) and the entire body of the recruit (183 specimens in total) was digested in $1.5 \mathrm{ml}$ and $30 \mu \mathrm{l}$ guanidine (CHAOS) solution, respectively, for several days. An equal volume of phenol extraction buffer (PEB) was added to the CHAOS solution just before DNA extraction. The total DNA was extracted from the CHAOS solution with PEB by phenol/chloroform extraction and ethanol precipitation, and resuspended in TE buffer with RNaseA (detailed compositions of each

off for DNA extraction and the remnant was placed in chlorine bleach for skeletal observation. To collect new recruits of Acropora corals, 6 sets of 3 artificial plates $(7.5 \times 7.5 \times 0.5 \mathrm{~cm}$, Fig. 2$)$ of unglazed tile were attached to the substratum, $2 \mathrm{~m}$ apart, using a stainless steel bolt. Three positions of the plate (upper, middle and lower) were prepared in order to examine whether the larvae prefer settling in a sunny or shaded area. These plates were set out at 4 different depths on Tomino Reef, and at 1 depth on Urasoko Reef in March of 2004, 2005 and 2006, 2 mo before the annual mass spawning event in May. All the plates disappeared from the reef crest due to strong wave action, excluding the reef crest from the recruitment study. In 2006, all the plates were retrieved 2 wk after the mass spawning event to obtain the recruits quickly after settlement, because in the previous years, when the plates had been left in place for over a month, many of the recruits had died.

Generally, the term 'recruit' implies individuals that have recently joined a population, and it is ambiguous as to when exactly an individual is no longer a recruit. In the present study, we define a recruit as an individual that has settled during the 2 wk period after a spawning event. Plates retrieved in 2004 to 2006 were observed under a stereo microscope and all recruits solution and buffer were described in Fukami et al. 2004). A part of the mitochondrial putative control region $\left(\mathrm{mtCR}_{i}\right.$ approximately $700 \mathrm{bp}$ of total $1200 \mathrm{bp}$; van Oppen et al. 2002) was used as the molecular marker for species identification. Because the evolutional rate of $\mathrm{mtCR}$ is faster than other mitochondrial genes, it is a suitable region for identification at species level in Acropora. PCR amplifications of the mtCR were conducted using the following primers: RNS2 5'-CAG AGT AAG TCG TAA CAT AG-3', and

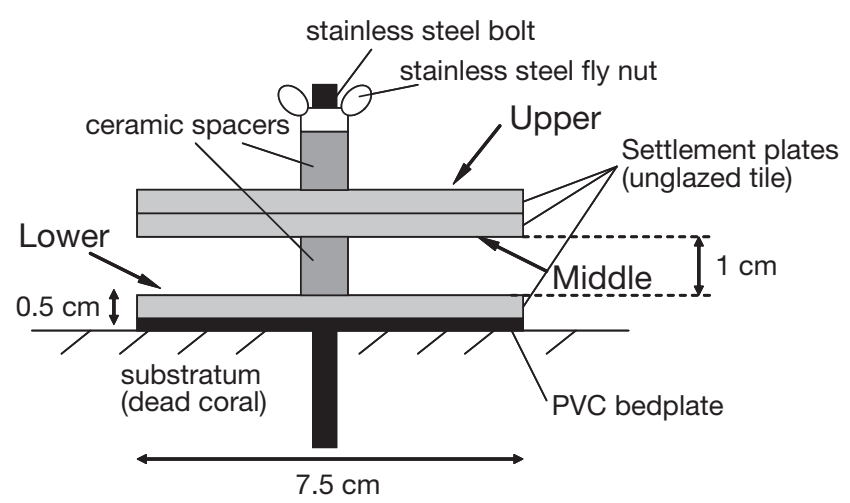

Fig. 2. A set of settlement plates for collection of coral recruits 
GR 5'-AAT TCC GGT GTG TGT TCT CT-3'. These primers were designed based on the whole mtDNA sequence of Acropora tenuis (van Oppen et al. 2002). The protocol for amplification was $94^{\circ} \mathrm{C}$ for $30 \mathrm{~s}$, followed by 30 cycles at $94^{\circ} \mathrm{C}$ for $20 \mathrm{~s}, 56^{\circ} \mathrm{C}$ for $30 \mathrm{~s}$ and $72^{\circ} \mathrm{C}$ for $90 \mathrm{~s}$, ending with a final phase of $72^{\circ} \mathrm{C}$ for 5 min. After an enzyme treatment with shrimp alkaline phosphatase (SAP) and exonuclease I (Exo I) at $37^{\circ} \mathrm{C}$ for $30 \mathrm{~min}, \mathrm{PCR}$ products were directly sequenced using PCR primers on an ABI 310 Genetic Analyzer. The DNA sequences obtained from recruits were compared with those of the adult colonies; only sequences that completely coincided were used as identifiers. When the recruit sequence did not match any of the adult sequences, it was considered to be an unidentified Acropora.

When multiple species shared the same mtCR haplotype, additional analysis using the nuclear marker 5.8S rDNA was conducted. The amplification of rDNA was conducted following Chen et al. (1995). The PCR products were cloned using a TA cloning kit (Invitrogen). Three clones from each sample were sequenced as described above. The nucleotide differences confirmed by the adult corals were used to identify the juveniles.

Statistical analysis. The differences in the number of recruits among depths and plate locations in each year (2004 to 2006) were analyzed by 2-way ANOVA. For 2004 and 2005 data, a general linear model was applied for the analyses because of the unbalanced experimental design. Urasoko $1.5 \mathrm{~m}$ sites were excluded from the analyses because there were too few recruits during the experimental periods. The Bonferroni $t$-test was performed for multiple comparisons. The effect of the year on coral recruitment was analyzed by repeated-measures ANOVA. The preference of plate location between depths was analyzed by 1-way ANOVA for each depth and year. The differences in species composition among recruits when compared against depth and location were analyzed by analysis of similarities (ANOSIM; Clarke \& Green 1988) using PRIMER software v. 5.2.8 (Primer-E). The null hypothesis $\left(\mathrm{H}_{0}\right)$ was that there would be no spatial variation in the number of recruits, independent of species. We treated depth as a factor and the number of recruits of each species per set of settlement plate (i.e. 6 replicates) at each depth and location as variables. To test the positive relationship between adult and recruits, a regression analysis was performed for each species. The coverage of adult colonies counted on the line transects and the percentage of recruits of each species were treated as an independent variable and dependent variables, respectively. All replicates within each depth were pooled in this analysis.

\section{RESULTS}

\section{Acropora coverage in each species}

The coverage of Acropora species was highest $(59.9 \%)$ on the middle reef slope $(5.5 \mathrm{~m})$ and lowest $(15.9 \%)$ on the reef crest $(1.5 \mathrm{~m})$ of Tomino Reef (Fig. 3). At the middle and deep depths, the branched coral A. muricata was most abundant and this resulted in the high coverage. In contrast, the numerically

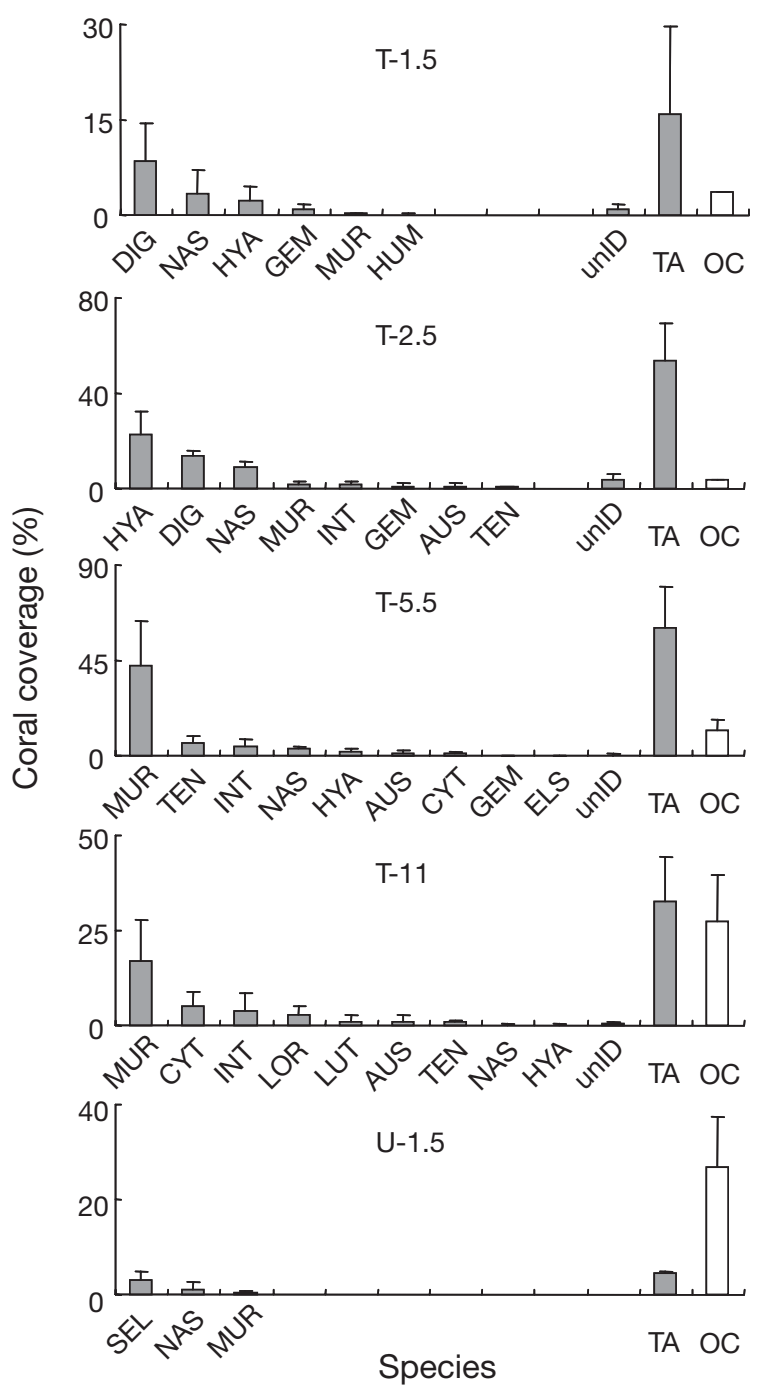

Fig. 3. Acropora spp. Average coral coverage along the 3 transects at each depth site: T-1.5, T-2.5, T-5.5 and T-11 are Tomino Reef $1.5,2.5,5.5$ and $11 \mathrm{~m}$ depth, respectively; U-1.5 is Urasoko Reef $1.5 \mathrm{~m}$ depth. DIG: A. digitifera, NAS: A. nasuta, HYA: A. hyacinthus, GEM: A. gemmifera, MUR: A. muricata, HUM: A. humilis, INT: A. intermedia, AUS: A. austera, TEN: A. tenuis, CYT: A. cytherea, ELS: A. elseyi, LOR: A. loripes, LUT: A. lutkeni, unID: unidentified Acropora (due to small colony size), TA: total Acropora, OC: other reef corals. Coral coverage was analyzed with the software program CPCe 
abundant tabular coral $A$. hyacinthus or the corymbose corals $A$. digitifera and $A$. nasuta were observed in the shallow waters (1.5 to $2.5 \mathrm{~m}$ ). Comparing the distribution of the 2 dominant species $A$. digitifera and A. hyacinthus, A. digitifera appeared to have adapted well to the shallow reef as it was the most abundant coral on the reef crest and no colonies were found deeper than $5.5 \mathrm{~m}$. A. hyacinthus was most abundant at $2.5 \mathrm{~m}$ depth and commonly observed at $5.5 \mathrm{~m}$. The corymbose coral A. tenuis was mainly distributed in the middle and deep areas and the tabular coral $A$. cytherea was recorded mainly at $11 \mathrm{~m}$. There were a few Acropora colonies $(4.5 \%)$ on the Urasoko Reef located in the inner bay. A. selago and A. nasuta were dominant, whereas $A$. selago was rare on Tomino Reef.

\section{Genetic identification of Acropora species}

From the results of the assessment of Acropora distribution (Fig. 3), we regarded 8 Acropora species as dominants, as each of these 8 species occured among the top 3 in at least one depth: A. digitifera, A. hyacinthus, A. muricata, A. nasuta, A. intermedia, A. selago, A. tenuis and $A$. cytherea. In addition, the 3 common species A. humilis, A. austera and A. loripes were used in the DNA analyses. In total, 103 mtCR sequences were obtained from these 11 species and submitted to the DNA Data Bank of Japan (DDBJ) (accession nos. AB361085 to AB361187). Analysis of DNA sequences of $\mathrm{mtCR}$ revealed several clades closely matched to each species, although there was haplotype variation

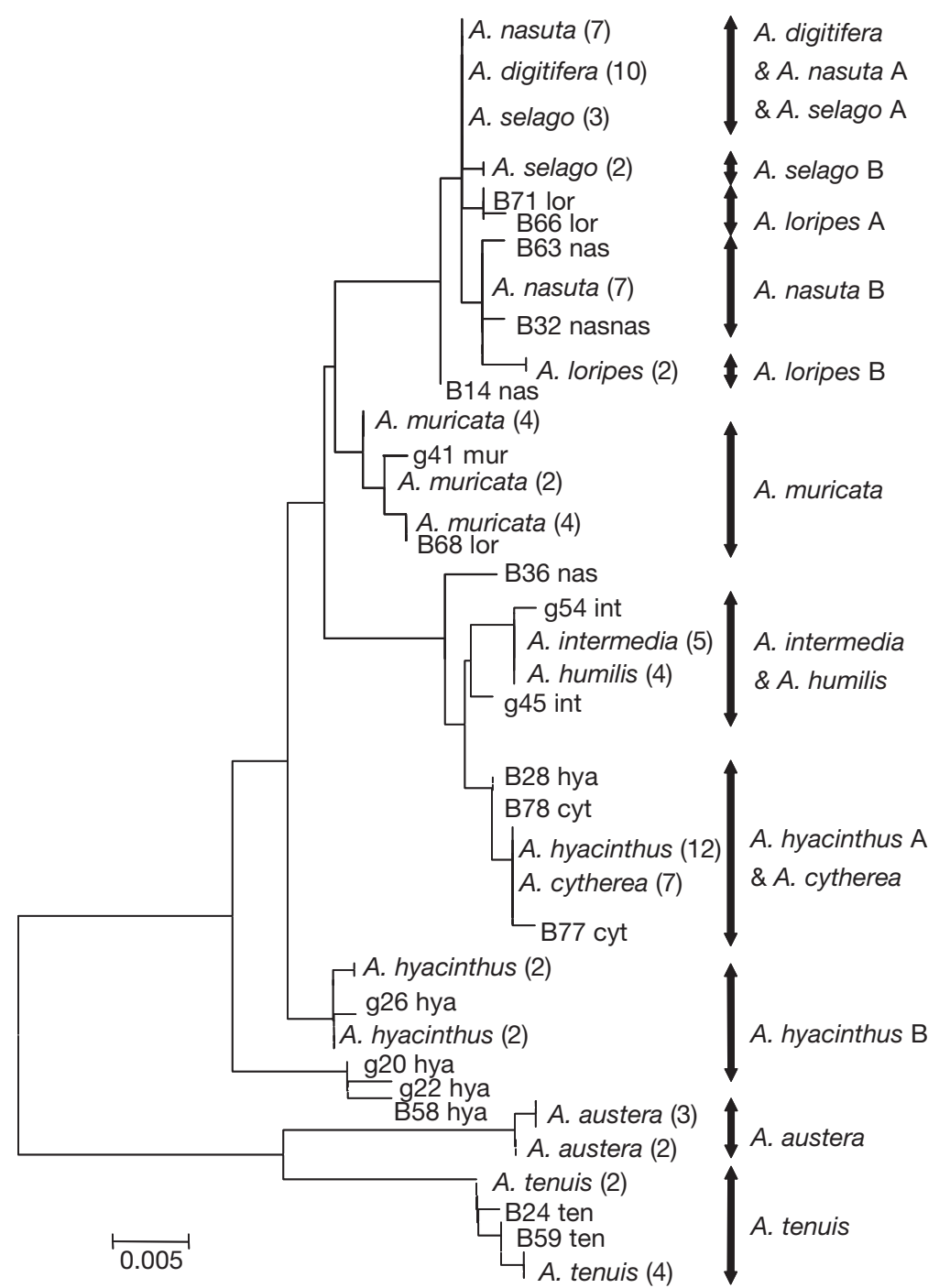

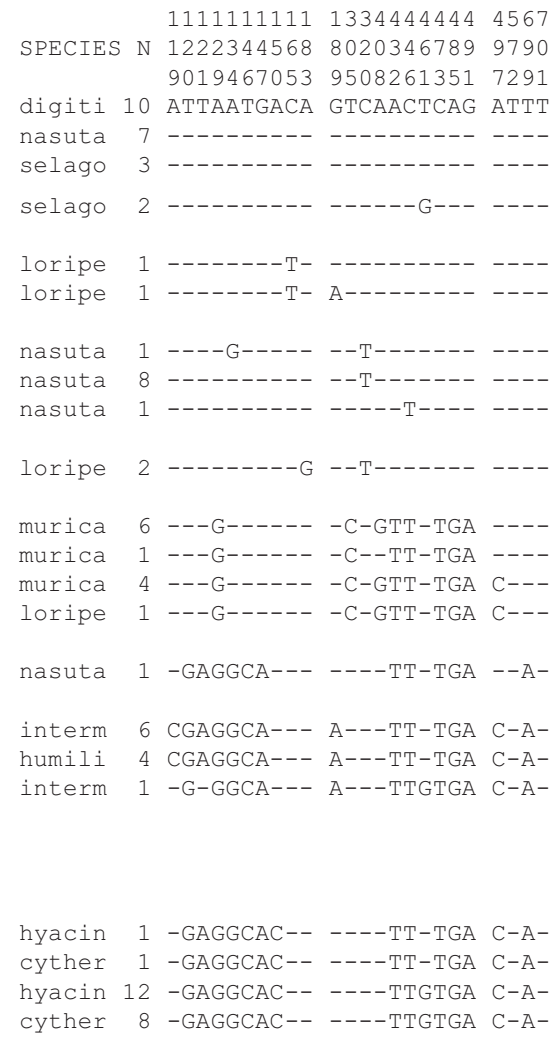

hyacin $3--\mathrm{A}------\mathrm{G}---\mathrm{CTT}-\mathrm{TGA}-\mathrm{G}-\mathrm{G}$ hyacin $2--\mathrm{A}-----\mathrm{T}----\mathrm{CTT}-\mathrm{TGA}-\mathrm{G}-\mathrm{G}$ hyacin $3--\mathrm{A}---------\mathrm{CTT}-\mathrm{TGA}-\mathrm{G}-\mathrm{G}$

Fig. 4. Acropora spp. Phylogenetic tree for the mtDNA control region constructed using the neighbor-joining method. Bootstrap values are not shown because the intention is to show clustering of specimens rather than genetic relationships. The number of colonies with the identical haplotype is indicated in parentheses. The sites providing species identification (total 24 positions) are shown on the right 
within most species (Fig. 4). The corymbose coral A. nasuta contained 2 main $\mathrm{mtCR}$ haplotypes (A and B) and shared A with 2 other species, A. digitifera and A. selago. The proportion of this haplotype was different among the species; 3 of $5 \mathrm{~A}$. selago and nearly half of $A$. nasuta grouped in the same clade with all of the $A$. digitifera. The rest of the A. selago specimens (haplotype B) clustered in a single clade that did not share haplotypes with any other corals. Twenty colonies of tabular coral A. hyacinthus contained 2 main haplotype groups (A and B), and the closely related species $A$. cytherea had the same haplotype as type A. $A$. intermedia and $A$. humilis also shared the same haplotype and formed a single clade. A. loripes, which was common in the deep sites, showed intense polyphyly; 1 specimen grouped with the A. muricata clade (this specimen had a slightly smaller axial corallite) and the others formed 2 clades (A and B). The early spawners $A$. tenuis and A. austera showed distinctly different haplotypes than the late spawners as previously reported (Fukami et al. 2003), and each constructed a single monophyletic cluster.

Additional analysis using the ribosomal 5.8S gene allowed identification of Acropora digitifera-A, A. nasuta-A and A. selago-A, which shared the same mitochondrial haplotype. Because rDNA is a multi-copy gene, each species had variant alleles but did not share them (53 alleles were submitted to DDBJ, accession nos. AB361188 to AB361240). Notably, on the end of $5.8 \mathrm{~S}$ regions, the 5 th position from the $3^{\prime}$ end was thymine in A. digitifera, and cytosine in A. nasuta-A, and for $A$. selago-A, the 5 th position was the same as in A. digitifera but the 4 th position had an insertion of thymine (Table 1). No distinguishing sequence posi-

Table 1. Acropora spp. Nuclear sequence of 3 species. Sequence represented by the last 7 bases on the ribosomal 5.8S gene; especially important are the 2 bases for species identification indicated in bold. Note that the number of colonies does not reflect single colonies; it counts a colony twice if it was sampled twice to catch different haplotypes in the same colony. Frequency means the percentage of the number of each sequence within species

\begin{tabular}{|c|c|c|c|c|}
\hline \multirow[t]{2}{*}{ Species } & \multirow[t]{2}{*}{ Sequence } & \multicolumn{2}{|c|}{ Number of } & \multirow[t]{2}{*}{ Frequency } \\
\hline & & Colonies & Clones & \\
\hline \multirow[t]{5}{*}{ A. digitifera } & CTT-GCT & 8 & 11 & 44.0 \\
\hline & CTT-GTT & 5 & 10 & 40.0 \\
\hline & GTT-GCT & 2 & 2 & 8.0 \\
\hline & CTT-GCA & 1 & 1 & 4.0 \\
\hline & CTT-GCC & 1 & 1 & 4.0 \\
\hline \multirow[t]{2}{*}{ A. nasuta } & CTC-GTT & 5 & 8 & 61.5 \\
\hline & CTC-GTC & 3 & 5 & 38.5 \\
\hline A. selago & СTTTGCT & 5 & 16 & 100 \\
\hline
\end{tabular}

tion was found for A. hyacinthus and A. cytherea. This 2-step genetic analysis was thus able to identify all dominant species of Acropora in the study area except A. hyacinthus and A. cytherea without morphological information.

\section{Annual recruitment}

The total number of recruits varied each year (repeated-measures ANOVA, $\mathrm{p}<0.001$ ) and the ratio of corals at each depth also changed on Tomino Reef (Fig. 5, Table 2). In 2004, the distribution of recruits concentrated in the shallow sites $(2.5 \mathrm{~m})$. This tendency did not change the next year, although the total number was approximately a tenth of that of the previous year.

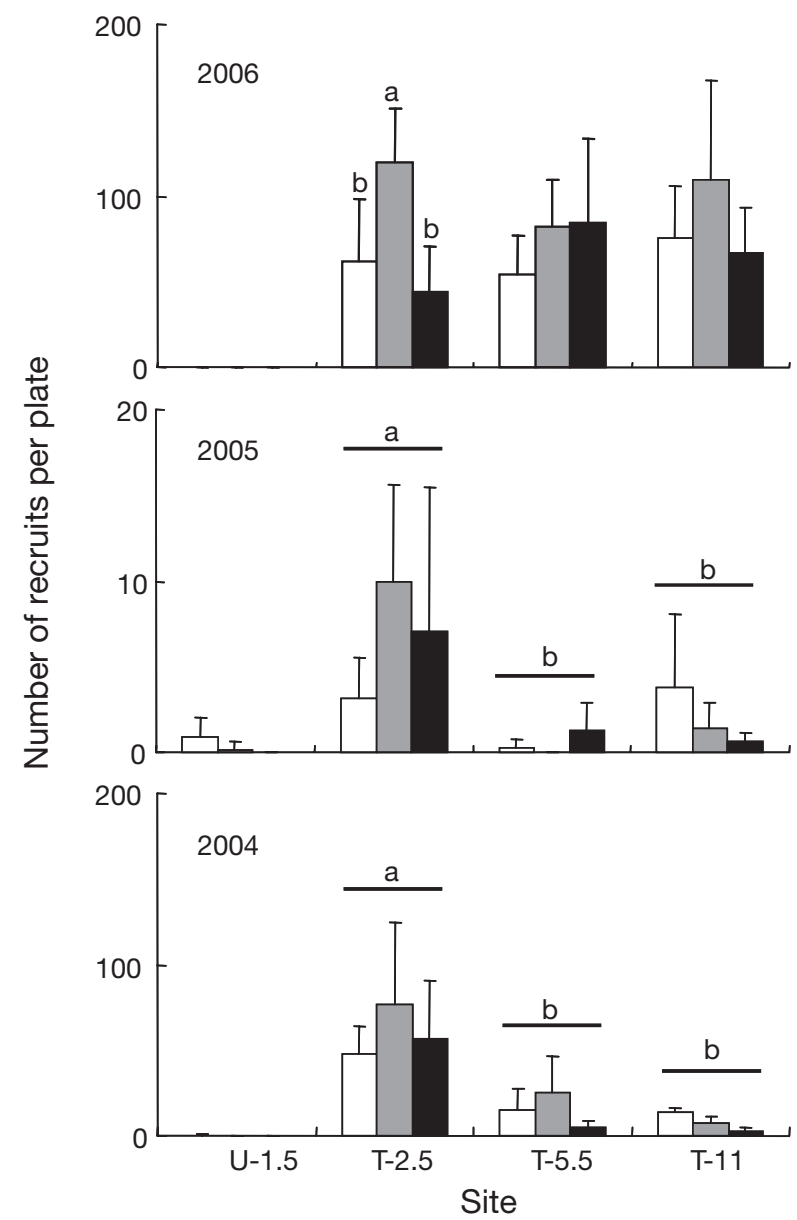

Fig. 5. Number of acroporid recruits during the 3 study years. Each bar represent the number of recruits on the upper (white), middle (grey) and lower (black) plates. Error bars show SDs. Note that the range of the vertical axis in 2005 is smaller than the other 2 years. Two-way ANOVA and Bonferroni $t$-test for multiple comparisons were used to determine the significant differences in the number of recruits (denoted by lower-case letters on the bars, see also Table 2). Site abbreviations are the same as in Fig. 3 
Table 2. Two-way ANOVA on the number of recruits on Tomino Reef. Factors were depth and location on plate. ns $=$ not significant

\begin{tabular}{|lrrrc|}
\hline Source & df & \multicolumn{1}{c}{ MS } & $F$ & $\mathrm{p}$ \\
\hline $\mathbf{2 0 0 4}$ & & & & \\
$\quad$ Depth & 2 & 11107.373 & 22.465 & $<\mathbf{0 . 0 0 1}$ \\
Location & 2 & 1020.398 & 2.064 & $\mathrm{~ns}$ \\
Depth $\times$ Location & 4 & 369.002 & 0.746 & $\mathrm{~ns}$ \\
Residual & 36 & 494.434 & & \\
Total & 44 & 1019.946 & & \\
$\mathbf{2 0 0 5}$ & & & & \\
Depth & 2 & 90.810 & 11.549 & $<\mathbf{0 . 0 0 1}$ \\
Location & 2 & 10.351 & 1.316 & $\mathrm{~ns}$ \\
Depth $\times$ Location & 4 & 18.661 & 2.373 & $\mathrm{~ns}$ \\
Residual & 30 & 7.863 & & \\
Total & 38 & 12.143 & & \\
$\mathbf{2 0 0 6}$ & & & & \\
Depth & 2 & 556.352 & 0.427 & $\mathrm{~ns}$ \\
Location & 2 & 9026.796 & 6.926 & $\mathbf{0 . 0 0 2}$ \\
Depth $\times$ Location & 4 & 2480.657 & 1.903 & $\mathrm{~ns}$ \\
Residual & 45 & 1303.281 & & \\
Total & 53 & 1655.407 & & \\
\hline
\end{tabular}

A total of 4176 recruits were counted in 2006, and there were no differences in the numbers found at the various depths. Analyzed according to year, the number of recruits differed by plate location (Fig. 5). More recruits were counted on the middle plates in shallow waters, while the upper plates were preferred at the deeper depth $(11 \mathrm{~m})$ in 2004 and 2005 (ANOVA, p < 0.01). In the Urasoko Reef, very few recruits were recorded throughout the experimental period. recruits of the branching species A. muricata were detected and only 4 specimens were identified as the complex of the branching coral $A$. intermedia and corymbose-shaped coral A. humilis. On the Urasoko Reef, there was only 1 recruit of Acropora and the molecular marker was identical to the A. intermedia \& A. humilis complex. Many recruits of the other 5 dominants were counted, and simple regression analysis revealed a strong correlation between the coverage of adults and the occurrence rate of recruits (Fig. 6) in 3 of them, A. digitifera $(\mathrm{r}=0.995, \mathrm{p}<0.01)$, A. hyacinthus$\mathrm{B}(\mathrm{r}=0.997, \mathrm{p}<0.01)$ and $A$. tenuis $(\mathrm{r}=0.991, \mathrm{p}<0.01)$. For A. hyacinthus, the analysis was conducted only for type B because $A$. hyacinthus-A recruits were indistinguishable from $A$. cytherea recruits. Only the cover of A. nasuta did not correlate with adult distribution $(\mathrm{r}=$ $0.312, \mathrm{p}>0.05)$.

More than $90 \%$ of all Acropora digitifera recruits were detected on the shallow slope $(2.5 \mathrm{~m})$ of Tomino Reef and only 1 specimen was found on the middle slope $(5.5 \mathrm{~m})$, representing approximately $20 \%$ of the total recruitment on the shallow slope. Seventy percent of $A$. tenuis recruits were found on the middle slope, and it was the most dominant species there, whereas only 1 recruit was identified in the shallow sites. Most recruits identified as $A$. hyacinthus-B were found on the shallow slope, whereas about half of the A. hyacinthus-A \& A. cytherea complex was counted on the deep slope $(11 \mathrm{~m})$. The other half of this complex was equally detected at the shallow and middle depths. The $A$. nasuta recruits were the most abundant of all

\section{Species composition of new recruits}

From the recruits on the plates in 2006, 182 specimens were analyzed by molecular markers. Forty-eight specimens were identified as the species complex of Acropora digitifera, A. nasuta and $A$. selago by mtCR (see Fig. 4). A total of 132 sequences of 5.8S rDNA were obtained from this complex, approximately $75 \%$ of which belonged to 3 species with nearly equal frequency. The remaining quarter represented hybrid patterns among the same 3 species.

The species composition of Acropora recruits was significantly different between Tomino and Urasoko Reefs, and also among the 3 depths sampled on the reef slope (Table 3, ANOSIM: R = 0.196, $\mathrm{p}<0.01$ ). Although there were 8 dominant species in the study area, no
Table 3. Acropora spp. Number of new recruits identified by the genetic markers in the study area. The dominant percentage of each species is in parentheses. Abbreviations of species names are identical to Fig. 3. Unanalyzed $=$ specimens where the genome was not obtained after 2 attempts of PCR amplification, Unidentified = Acropora species that did not match any of the adult haplotypes found

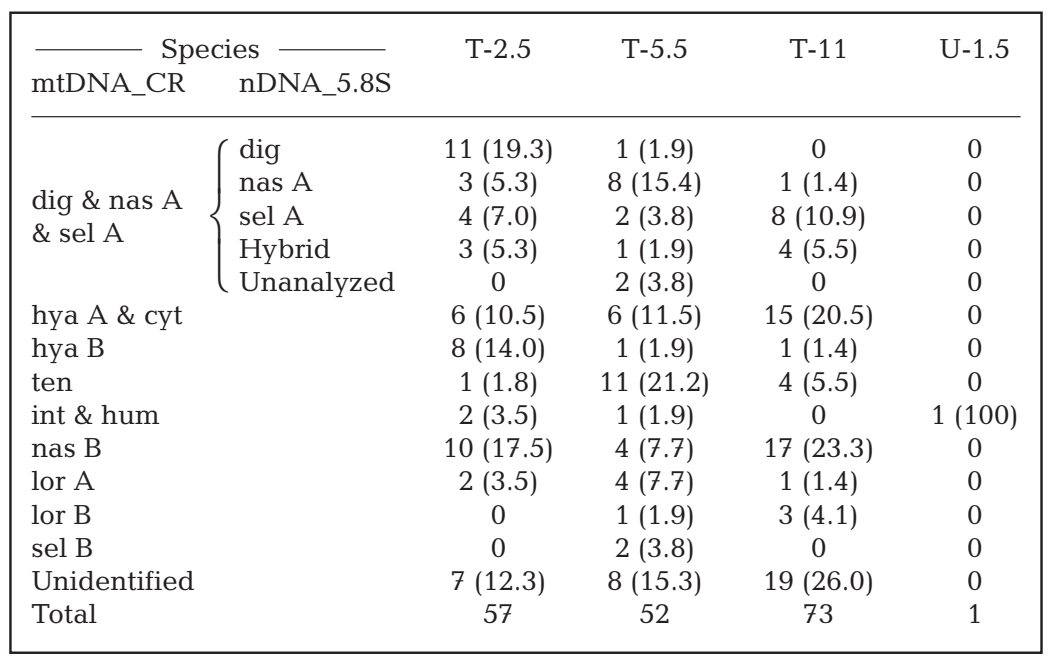




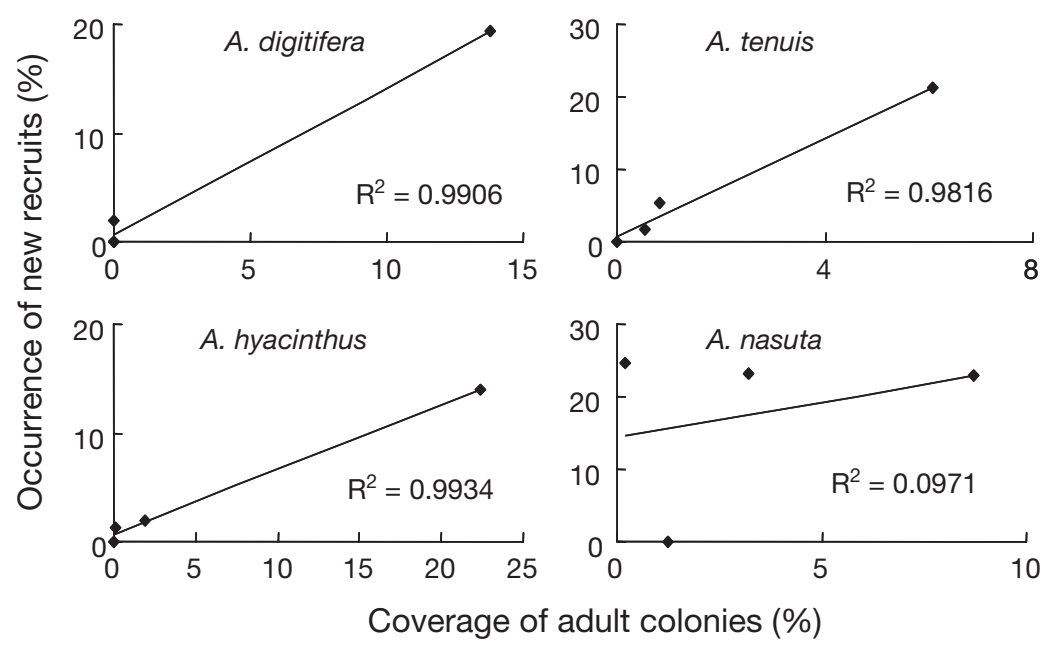

Fig. 6. Acropora spp. Relationships between the occurrence of new recruits and the number of adult colonies at each depth (except for the reef crest at Tomino Reef)

analyzed specimens, and each haplotype had a different settlement preference, concentrated in the middle (two-thirds of type A) or deep (more than half of type B) habitat. In the case of $A$. selago, which was unrecorded on Tomino Reef as an adult, some recruits were observed at all depths and were recorded as the third most dominant recruit $(10.9 \%)$ in the deep water. Nearly $20 \%$ of the analyzed specimens were unidentifiable to species level by the 2 markers, but interestingly, their distribution was not equal among the depths, as more than twice as many were found in the deep waters than in the shallow or middle slope.

There were no significant differences in settlement location between species (data not shown). While many recruits settled on the middle or lower plates and on the groove between the upper and middle plate, only recruits of Acropora tenuis showed a remarkable bias in that they never settled on the upper plate. To determine if larvae belonging to a single species share a preference for settlement place, their positions on the plate were examined. Although the case of $>3$ individuals completely fused with each other was not tested, no aggregated settlement of conspecific individuals was found; multiple species existed within a range of a few millimeters from each other on the plates.

\section{DISCUSSION}

\section{Utility of the molecular markers}

In this study, we adopted a 2-step molecular technique for the identification of Acropora species. Among the 8 dominant species in the area, the 3 spe- cies $A$. tenuis, A. intermedia and A. muricata were almost completely distinguishable by the first marker, mtCR. Mitochondrial DNA is inherited maternally and so an individual has a single haplotype. The sequences of $\mathrm{mtCR}$ have larger variation than functional genes, enabling a quick analysis by direct sequencing, and suggesting the suitability of the first marker for distinguishing between these species. Multiple species that share a similar haplotype (e.g. A. digitifera, A. selago and A. nasuta) most likely represent a recent speciation or hybridization (van Oppen et al. 2001) and further identification requires a second step using a nuclear marker. These 3 species could be separated by their 5.8S rDNA, suggesting that this gene reflects the current reproductive barrier. Importantly, this technique allows the identification of the recruits of the most dominant Acropora species in the study area which had been recorded only as 'Acropora spp.' in the previous years using morphological traits.

This method will not be usable in all coastal regions to distinguish between dominant species due to differences in species composition. For example, Acropora humilis and A. intermedia had the same mitochondrial haplotype even with completely different morphologies. In addition, many Acropora species can hybridize under laboratory conditions (Willis et al. 1997, Hatta et al. 1999), which may result in polyphyly in some species such as $A$. hyacinthus and $A$. cytherea. This was the only case that could not be distinguished between dominant species with both markers. However, the use of the second marker confirmed that these species have a statistically distinguishable lineage (Márquez et al. 2002a). In the Tomino and Urasoko Reefs, these problems did not affect the identification of the dominant species. However, it may cause difficulty in the identification of recruits in situations where many dominants share the same sequence, and thus, the genetic relation of the dominant species should always be examined during the preliminary stages of an assessment.

\section{Selective settlement of Acropora species}

In all dominant species, except for the 2 branching species Acropora muricata and A. intermedia, many recruits were identified. Within these species, the recruits of $A$. digitifera, $A$. tenuis and $A$. hyacinthus showed significant bias among depths, and this bias 
was consistent with adult distribution. The species composition of recruits was roughly the same as that of adults, suggesting that these recruits were derived from the local population. The compositions differed by reef; for instance, $A$. gemmifera and $A$. monticulosa were more abundant than $A$. nasuta and $A$. digitifera in Urasaki and Shiraho Reefs, on the east coast of Ishigaki Island (our Fig. 1a; Sugihara et al. 2003). Considering that the mtCR haplotype of $A$. gemmifera and A. monticulosa is more similar to $A$. humilis than A. nasuta and A. digitifera (Wolstenholme 2004), and that the haplotype was rare in the recruits on Tomino Reef, larvae from the distant reef were unlikely to reach this study site. It may be that the local current causes the larvae originating from the coastal area around the study reefs to accumulate without extensive dispersal.

Almost all the Acropora digitifera recruits settled on the shallow part of Tomino Reef. Adult colonies of this species were mainly observed in the wave-exposed habitat and their skeletons seemed to be very thick, which may be an adaptation to the stress of strong water action. Considering that they die easily (compared to other corals) when cultured under weak current conditions (G. Suzuki pers. obs.), this species might not be able to survive without strong water movement. The tabular coral A. hyacinthus seemed to settle on both shallow and deep slopes, but it should be noted that there was a different gradient along the depths between haplotypes; the frequency of type A was much higher than type B in the deeper waters. Considering that type A contained the closely related species A. cytherea, which is commonly observed in deep habitats $(>10 \mathrm{~m}$ ) on Tomino Reef, the gradient might be the result of different preferences for settlement of the 2 species. These species were able to crossfertilize during artificial hybridization (Willis et al. 1997) but they have genetically distinct allozymes (Márquez et al. 2002b). The results of the present study suggest that they have distinct habitats which are established by the ecological preferences of larval settlement. Most recruits of the corymbose coral A. tenuis, whose skeleton is fragile and easily broken when touched, were recorded at $5.5 \mathrm{~m}$. While other corymbose corals dominated in the shallow zones (2 to $5 \mathrm{~m}$ ), only this thin-skeleton species was abundant along the middle or deep slopes (Fig. 3). We have observed that the larvae of $A$. tenuis had the longest peak of successful settlement in rearing tanks (>10 d), whereas A. digitifera and $A$. hyacinthus settled and metamorphosed on the wall of the aquarium within $1 \mathrm{wk}$ after fertilization (see also Morse et al. 1996). This may suggest that A. tenuis larvae are able to stay suspended for longer periods, which may contribute to selective settlement on deep habitats involving suspension in the water column. The fact that half of the A. selago juveniles settled on the deep slope (Table 3 ) seems to be contradictory to the distribution pattern seen in the adults that commonly inhabit in the inner reef area (i.e. Urasoko Reef). However, a similar water environment between the deep slope and inner bay (i.e. weak wave stress and low light intensity) likely contributed to this phenomenon.

As the recruits were collected within 2 wk of spawning, we expected that there would be little initial mortality of the settlers (supported by the presence of only a few juvenile skeletons) and that the species composition of analyzed specimens represented the actual frequency of larvae that settled. Accordingly, our data strongly indicates that coral larvae settled selectively on the preferred habitat. Larval ability to sense environmental information seems to be suggested because they were distinguishing between very small differences in depth. From this evidence, it is clear that the larval selectivity for settlement plays at least some part in establishing the pattern of zonation even at the species level within a genus. In addition, although there has been laboratory evidence for larval selective settlement in the higher taxonomic zonation (e.g. Mundy \& Babcock 1998, Baird et al. 2003), the present study is the first confirmation of this tendency in a field survey.

\section{Incongruent relation between recruits and adults}

The larvae of Acropora nasuta did not show a preference for settling at a certain depth. This tendency does not correspond with the adult distribution that dominates in the shallow water. Considering the difference of habitat preference between haplotypes, the presence of a cryptic species is suspected. Moreover, because there was no positive correlation between the recruitment and depth in this species, A. nasuta-B larvae are unlikely to be guided by depth-related variables (e.g. light intensity). Biological factors such as algae, sessile animals, bacteria or other microorganisms can contribute to the attraction or avoidance of an area. Indeed, coral larvae did show a preference for metamorphosing on older biofilms (8 wk old compared with 2 wk old) and for films that were established in shallow water $(4 \mathrm{~m})$ compared with deep water $(12 \mathrm{~m})$ (Webster et al. 2004). The substratum of middle depths was dominated by filamentous algae, probably due to culturing by territorial damselfish Plectroglyphidodon lacrymatus, which may have caused the larvae to avoid settling there during the recruitment experiments. The finding that $A$. nasuta was the only species commonly distributed on both the outer and inner reefs (Fig. 3) supports this depthindependent settlement behavior. 
Almost no recruits were detected for the 2 branching corals Acropora muricata and A. intermedia $(<2 \%$ of the total), even though their spawning was synchronous with the other dominant Acropora, judging from the observation of fecundity in the field and spawning behavior in the laboratory. Two reasons are suspected for this result. First, the number of fertilized eggs per colony of these species might be fewer than those of tabular or corymbose corals. The 2 types have different reproductive strategies: branching species mainly recruit from fragments (asexually) while tabular and corymbose species recruit predominantly from larvae (Wallace 1985a, Nakamura \& Nakamori 2006). In general, 'fragmenters' have fewer larval recruits than 'non-fragmenters' (Wallace 1985a). This may be the cause of the low level of branching species recruits found on the Tomino and Urasoko Reefs. Alternatively, it is possible to speculate that larvae of these species could not settle on the plates due to the difference of habitat preference from other species. However, such differences have not been found previously, nor is there any reason to think that they are unable to settle on hard substratum (G. Suzuki unpubl. data). So, at this time, the former explanation is more plausible.

\section{Relative importance of larval settlement in habitat segregation}

Comparing the recruitment tendency among years, the number of juveniles was biased towards the shallow zone in 2 of the 3 study years (Fig. 5). These depthdependent gradients of Acropora recruits are probably general in any region (e.g. Wallace 1985b), and must underpin the numerical dominance of corymbose and tabular species in shallow habitats. On the other hand, fewer recruits in the deep habitat were counted during the first 2 yr. If fewer gametes or the larvae of depthpreferring species caused this tendency, the asynchronous spawning would often isolate the species groups in deep habitats from those in shallow ones.

Many factors affect coral distribution: larval swimming, settlement, acquisition of symbiotic algae, competition with other sessile organisms and natural disturbances such as typhoons. Each factor would be expected to have a different role in sustaining the zonation structure. The present study looked at the initial life stage and the importance of selective settlement. Pre-settlement behavior is most likely also involved in establishing distribution patterns by means of selective settlement attained by species-specific swimming abilities depending on the gradient of light quantity. Larval sensitivity to high-intensity light (Wellington \& Fitt 2003, Suzuki \& Hayashibara 2006) supports this hypothesis. Our results of Acropora larvae selectively settling on the middle plate in the shallow waters and on the upper plate in the deep waters (Fig. 5) also suggest that they utilize ambient light intensity for settling on a suitable place. Furthermore, for A. tenuis larvae, the settlement competency period is likely to determine habitat depth, whereas it was previously thought to simply limit their dispersal range (e.g. Miller \& Mundy 2003). The presence of few zooxanthellae in most recruits (at least invisible under a microscope) also supports the importance of larval behaviors by suggesting that it is independent of the uptake of symbiotic algae. Although post-settlement survival, especially during the first few years, could affect final coral distribution, there was no significant difference in initial survival among 4 Acropora species (A. digitifera, A. tenuis, A. muricata and A. selago) in any depths on Tomino Reef at least during the half year after the settlement (G. Suzuki \& T. Hayashibara unpubl. data). Accordingly, pre-settlement behavior is the most influential factor in determining coral zonation. This is beneficial to understanding not only the mechanism of zone formation but also evolutional aspects such as speciation in reef corals.

Acknowledgements. This study was a collaborative effort between the Seikai National Fisheries Research Institute and Kyoto University. We thank H. Shimizu, M. Katoh, M. Tamaki and R. Fuseya for extending research facilities to us. G.S. specifically thanks $\mathrm{H}$. Toyohara for giving him a chance to participate in this study. We also thank P. R. Rigby for polishing the manuscript. Financial support was partially provided by the Mikimoto Fund for Marine Ecology for 2005 to H.F. and a grant to H.F. from the Japan Society for the Promotion of Science (no. 18770013). The sampling of corals was permitted by the Okinawa Prefectural Government.

\section{LITERATURE CITED}

Adjeroud M (1997) Factors influencing spatial patterns on coral reefs around Moorea, French Polynesia. Mar Ecol Prog Ser 159:105-119

Andre C, Lindegarth M, Jonsson PR, Sundberg P (1999) Species identification of bivalve larvae using random amplified polymorphic DNA (RAPD): differentiation between Cerastoderma edule and C. lamarcki. J Mar Biol Assoc UK 79:563-565

Babcock RC, Mundy CN (1996) Coral recruitment: consequences of settlement choice for early growth and survivorship in two scleractinians. J Exp Mar Biol Ecol 206:179-201

Babcock RC, Baird AH, Piromvaragom S, Thomson DP, Willis BL (2003) Identification of Scleractinian coral recruits from Indo-Pacific reefs. Zool Stud 42:211-226

Baird AH, Babcock RC (2000) Morphological differences among three species of newly settled pocilloporid coral recruits. Coral Reefs 19:179-193

Baird AH, Babcock RC, Mundy CN (2003) Habitat selection by larvae influences the depth distribution of six common coral species. Mar Ecol Prog Ser 252:289-293

Carlon DB (2002) Production and supply of larvae as determinants of zonation in a brooding tropical coral. J Exp Mar Biol Ecol 268:33-46

Chen CA, Odorico DM, Ten Lohuis M, Veron JEN, Miller DJ (1995) Systematic relationships within the Anthozoa 
(Cnidaria: Anthozoa) using 5' end of the 28S rDNA. Mol Phylogenet Evol 4:175-183

Clarke KR, Green RH (1988) Statistical design and analysis for a 'biological effects' study. Mar Ecol Prog Ser 46:213-226

Dollar SJ (1982) Wave stress and coral community structure in Hawaii. Coral Reefs 1:71-81

Done TJ (1982) Patterns in the distribution of coral communities across the central Great Barrier Reef. Coral Reefs 1: 95-107

Evans BS, White RWG, Ward RD (1998) Genetic identification of asteroid larvae from Tasmania, Australia, by PCR-RFLP. Mol Ecol 7:1077-1082

Fujioka Y (1998) Checklist of the hermatypic corals of Urasoko Bay, Ishigaki Island, Southwestern Japan. Bull Nansei Natl Fish Res Inst 31:1-11

Fukami H, Omori M, Shimoike $\mathrm{K}$, Hayashibara T, Hatta M (2003) Ecological and genetic aspects of reproductive isolation by different spawning times in Acropora corals. Mar Biol 142:679-684

Fukami H, Budd AF, Levitan DR, Jara J, Kersanach R, Knowlton N (2004) Geographic differences in species boundaries among members of the Montastraea annularis complex based on molecular and morphological markers. Evolution 58:324-337

Graus RR, Macintyre IG (1989) The zonation patterns of Caribbean coral reefs as controlled by wave and light energy input, bathymetric setting and reef morphology: computer simulation experiments. Coral Reefs 8:9-18

Hatta M, Fukami H, Wang W, Omori M and others (1999) Reproductive and genetic evidence for a reticulate evolutionary history of mass-spawning corals. Mol Biol Evol 16: 1607-1613

Jeffery CJ (2002) New settlers and recruits do not enhance settlement of a gregarious intertidal barnacle in New South Wales. J Exp Mar Biol Ecol 275:131-146

Kohler KE, Gill SM (2006) Coral Point Count with Excel extensions (CPCe): a Visual Basic program for the determination of coral and substrate coverage using random point count methodology. Comput Geosci 32:1259-1269

Lindstrom DP (1999) Molecular species identification of newly hatched Hawaiian amphidromous gobioid larvae. Mar Biotechnol 1:167-174

Márquez LM, van Oppen MJH, Willis BL, Reyes A, Miller DJ (2002a) The highly cross-fertile coral species, Acropora hyacinthus and Acropora cytherea, constitute statistically distinguishable lineages. Mol Ecol 11:1339-1349

Márquez LM, van Oppen MJH, Willis BL, Miller DJ (2002b) Sympatric population of the highly cross-fertile coral species Acropora hyacinthus and Acropora cytherea are genetically distinct. Proc R Soc Lond B 269:1289-1294

Miller K, Mundy C (2003) Rapid settlement in broadcast spawning corals; implications for larval dispersal. Coral Reefs 22:99-106

Morse ANC, Iwao K, Baba M, Shimoike K, Hayashibara T, Omori M (1996) An ancient chemosensory mechanism brings new life to coral reefs. Biol Bull (Woods Hole) 191: 149-154

Mundy CN, Babcock RC (1998) Role of light intensity and spectral quality in coral settlement: implications for depthdependent settlement? J Exp Mar Biol Ecol 223:235-255

Mundy C, Babcock R (2000) Are vertical distribution pattern of scleractinian corals maintained by pre- or post-settlement processes? A case study of three contrasting species. Mar Ecol Prog Ser 198:109-119

Nakamura T, Nakamori T (2006) Population dynamics of hermatypic coral communities on reef slope vs. reef flat at Shiraho, Ishigaki Island, southwest Japan. Proc 10th Int
Coral Reef Symp 2:460-477

Raimondi PT, Morse ANC (2000) The consequences of complex larval behavior in a coral. Ecology 81:3193-3211

Rogers CS (1990) Responses of coral reefs and reef organisms to sedimentation. Mar Ecol Prog Ser 62:185-202

Shearer TL, Coffroth MA (2006) Genetic identification of Caribbean scleractinian coral recruits at the Flower Garden Banks and the Florida Keys. Mar Ecol Prog Ser 306: 133-142

Sheppard CRC (1980) Coral cover, zonation and diversity on reef slopes of Chagos Atolls, and population structures of the major species. Mar Ecol Prog Ser 2:193-205

Sugihara K, Nakamori T, Iryu Y, Sasaki K, Blanchon P (2003) Holocene sea-level change and tectonic uplift deduced from raised reef terraces, Kikai-jima, Ryukyu Islands, Japan. Sedim Geol 159:5-25

Suzuki G, Hayashibara T (2006) Inhibition of settlement and metamorphosis in Acropora (Anthozoa, Scleractinia) larvae by high-intensity light. Proc 10th Int Coral Reef Symp 4:1627-1630

Thiyagarajan V, Lau SCK, Cheung SCK, Qian P (2006) Cypris habitat selection facilitated by microbial films influences the vertical distribution of subtidal barnacle Balanus trigonus. Microb Ecol 51:431-440

Titlyanov EA, Latypov YY (1991) Light-dependence in scleractinian distribution in the sublittoral zone of South China Sea Islands. Coral Reefs 10:133-138

Underwood AJ, Denley EJ (1984) Paradigms, explanations, and generalizations in models for the structure of ecological communities on rocky shores. In: Strong D, Simberloff D, Abele LG, Thistle AB (eds) Ecological communities: conceptual issues and the evidence. Princeton University Press, Princeton, NJ, p 151-180

van Oppen MJH, Catmull J, McDonald BJ, Hislop NR, Hagerman PJ, Miller DJ (2002) The mitochondrial genome of Acropora tenuis (Cnidaria; Scleractinia) contains a large group I intron and a candidate control region. J Mol Evol 55:1-13

van Oppen MJH, McDonald BJ, Willis B, Miller DJ (2001) The evolutionary history of the coral genus Acropora (Scleractinia, Cnidaria) based on a mitochondrial and a nuclear marker: reticulation, incomplete lineage sorting, or morphological convergence? Mol Biol Evol 18:1315-1329

Wallace CC (1985a) Reproduction, recruitment and fragmentation in nine sympatric species of the coral genus Acropora. Mar Biol 88:217-233

Wallace CC (1985b) Seasonal peaks and annual fluctuation in recruitment of juvenile scleractinian corals. Mar Ecol Prog Ser 21:289-298

Wallace CC, Dale MB (1979) An information analysis approach to zonation patterns of the coral genus Acropora on the outer reef butresses. Atoll Res Bull 220:98-110

Webster NS, Smith LD, Heyward AJ, Watts JEM, Webb RI, Blackall LL, Negri AP (2004) Metamorphosis of a scleractinian coral in response to microbial biofilms. Appl Environ Microbiol 70:1213-1221

Wellington GM, Fitt WK (2003) Influence of UV radiation on the survival of larvae from broadcast-spawning reef corals. Mar Biol 143:1185-1192

Willis BL, Babcock RC, Harrison PL, Wallace CC (1997) Experimental hybridization and breeding incompatibilities within the mating systems of mass spawning reef corals. Coral Reefs 16(Suppl):S53-S65

Wolstenholme JK (2004) Temporal reproductive isolation and gametic compatibility are evolutionary mechanisms in the Acropora humilis species group (Cnidaria; Scleractinia). Mar Biol 144:567-582

Submitted: July 3, 2007; Accepted: September 15, 2007

Proofs received from author(s): January 31, 2008 